EM

\title{
CONSIDERAÇÕES SOCIOAMBIENTAIS SOBRE AS CHUVAS INTENSAS NAS PRINCIPAIS CIDADES DA REGIÃO METROPOLITANA DE MACEIÓ: UM OLHAR DA POPULAÇÃO
}

\section{SOCIO-ENVIRONMENTAL CONSIDERATIONS ABOUT THE RAINSTORMS IN MAJOR CITIES OF MACEIÓ METROPOLITAN REGION: A VIEW FROM THE POPULATION}

\author{
Melchior Carlos NASCIMENTO ${ }^{1}$ \\ Esdras de Lima ANDRADE ${ }^{2}$ \\ Sinval Autran Mendes GUIMARÃES JÚNIOR ${ }^{3}$
}

\begin{abstract}
Resumo: A ocupação irregular dos espaços urbanos tem provocado prejuízos diversos às metrópoles brasileiras, comprometendo a eficiência dos serviços públicos como abastecimento de água, esgotamento sanitário, transporte e importantes serviços essenciais à garantia da qualidade de vida. Desta maneira, os problemas decorrentes das ocupações irregulares nas principais cidades que integram a Região Metropolitana de Maceió - RMM tem alcançado mais evidencia quando da ocorrência das precipitações pluviométricas. Assim, o presente estudo teve a finalidade de avaliar a opinião socioambiental dos habitantes residentes em áreas vulneráveis aos eventos relacionados às chuvas intensas. Para tanto, foram realizadas entrevistas com auxílio de questionário, que considerou a população amostral correspondente a um total de 625 pessoas, residente nos setores censitários com muito baixa, baixa, média, alta e muito alta vulnerabilidades socioambientais. Dentre os resultados, observou-se que as populações residentes nessas áreas, sensíveis aos problemas de alagamentos, deslizamento de terra ou enchentes encontram-se relativamente fragilizadas sob o ponto de vista social e que a ocorrência desses variados tipos de eventos na RMM depende da interveniência das chuvas.
\end{abstract}

Palavras-Chaves: Vulnerabilidade socioambiental; Alagamentos; Deslizamento de terra; Enchente e educação ambiental.

\begin{abstract}
The irregular occupation of the urban spaces has caused several damages to Brazilian metropolises, compromising the efficiency of the public services such as water supply, sanitation, transportation and important services essential to guarantee the quality of life. In this way, the problems resulting from irregular occupations in the major cities that are part of the Metropolitan Region of Maceió - MRM - have achieved more evidence when rainfall occurs. Therefore, the present study proposes to evaluate the socio-environmental opinion of the inhabitants living in areas vulnerable to events related to intense rains. Interviews were conducted with the aid of a questionnaire, which considered the sample population corresponding to a total of 625 people, residing in the census sectors with very low, low, medium, high and very high socio-environmental vulnerabilities. It was noted that the population living in areas vulnerable to the problems of inundation, landslides or floods are relativily weakened in a social perspective and that the occurence of these different kinds of events in the MRM depends of the rainfall interference.
\end{abstract}

Keywords: Socio-environmental vulnerability; Inundation; Landslides; Floods and environmental

\footnotetext{
${ }^{1}$ Professor da Universidade Federal de Alagoas, Instituto de Geografia, Desenvolvimento e Meio Ambiente, Programa de Pós-Graduação em Geografia. Maceió - Alagoas.

${ }^{2}$ Geógrafo da Universidade Federal de Alagoas, Instituto de Geografia, Desenvolvimento e Meio Ambiente. Maceió - Alagoas.

${ }^{3}$ Professor da Universidade Federal de Alagoas, Instituto de Geografia, Desenvolvimento e Meio Ambiente. Maceió - Alagoas.
} 
$\mathrm{EM}$

QUESTÃO

Introdução

Os relatórios produzidos pelo Painel Intergovernamental sobre Mudanças Climáticas (IPCC) indicam uma estreita relação entre as intervenções humanas e as alterações das condições climáticas do planeta. Diante dessa constatação, os especialistas e pesquisadores das diversas partes do mundo têm mobilizado seus esforços em busca de respostas sobre o que é possível ser feito (ALMEIDA, 2007). Nas áreas urbanas, os transtornos com o desconforto térmico, os problemas de deslizamentos de terra, os alagamentos e as inundações decorrentes das chuvas intensas são as ocorrências mais frequentes. De acordo com Campbell-Lendrum e Corvalán (2007), as grandes cidades deverão se tornar mais vulneráveis ao aquecimento e às inundações por serem geradoras de calor e pela impermeabilização do solo com construções que diminuem a capacidade de percolação de águas das chuvas.

Em âmbito regional, embora a maior parte do nordeste brasileiro ainda seja consideravelmente afetada pelos prolongados períodos de estiagem, com aproximadamente $60 \%$ da sua extensão suscetível aos efeitos da seca, os episódios associados aos extremos climáticos relacionados às chuvas intensas também têm causado consequências danosas às áreas urbanas, especialmente as mais adensadas. Apesar de as chuvas terem provocado prejuízos consideráveis, a falta de infraestrutura adequada ainda continua sendo a principal responsável, pois a maior parte das cidades brasileiras não contou com um processo planejado de urbanização, tendo suas encostas e áreas suscetíveis a alagamento e inundação ocupadas inadequadamente.

No caso da Região Metropolitana de Maceió - RMM, as intervenções que promoveram alterações em sua paisagem natural tiveram início durante o século XVI, nas primeiras incursões mercantilistas ao Brasil. De acordo com Andrade (2010, p.21), o processo de povoamento da região foi determinado pela cultura da cana-de-açúcar, que ocupou preferencialmente as várzeas dos rios que desembocam no Oceano Atlântico. Assim sendo, a faixa costeira do estado de Alagoas, por ter sido a primeira a ser ocupada, teve suas florestas substituídas pelos canaviais e habitações.

Diante desse contexto, pode-se dizer que o crescimento das cidades que integram a RMM e, consequentemente, o seu processo de povoamento foram marcados por distorções espaciais que influenciaram de maneira decisiva a evolução urbana e o seu desenvolvimento social. De acordo com Costa (2001), a partir da última década do século XIX, tendo em vista a importância cultural, econômica e política da cidade de Maceió, esta experimentou um surto de crescimento, quando a 
EM

QUESTÃO

V.14 N. $01 \bullet 2021$

pág. 180-208

população passou a dispor de novo ambiente fisiográfico para desenvolver-se. Para este autor, a cidade cresceu desordenadamente, sem ritmo, sem método, sem estilo.

Embora as regiões norte e sul do território do atual estado de Alagoas também tivessem importantes núcleos de povoamento, os municípios pertencentes à RMM já alcançavam uma posição relevante no conturbado e embrionário processo de urbanização da antiga província de Alagoas. De acordo com Espindola (2001, p. 77), do total de 310.567 habitantes contabilizados em 1860, aproximadamente, 37,03\% (115.027 pessoas) residiam nos povoamentos das freguesias da atual área de estudo. Na medida em que as cidades se tornavam atrativas, especialmente a capital Maceió, os problemas decorrentes da ocupação desordenada foram revelando ainda mais o nível de vulnerabilidade dos povoamentos que integravam a atual RMM. Apenas a partir das primeiras décadas do século XX, essas cidades passaram a sofrer com os problemas socioambientais decorrentes de um processo indiscriminado de urbanização.

É importante observar que, nos municípios que integram a RMM, as chuvas intensas associadas às precárias condições de infraestrutura básica têm sido as principais causas pelos problemas de alagamentos, desabamentos, enchentes e inundações. Embora Maceió ainda seja a cidade mais afetada pelas chuvas intensas, até mesmo por se tratar do núcleo populacional mais adensado e devido ao seu processo desordenado de ocupação, as demais cidades também têm sido fortemente atingidas, entre outros fatores, também por possuírem uma precária infraestrutura.

Dentre os eventos que atingem os municípios inseridos na área de estudo, os mais significativos estão associados à elevação do nível ou transbordamento d'água nas áreas sob influência dos rios Manguaba e Mundaú e das respectivas lagunas homônimas. Por se tratar de áreas razoavelmente adensadas, com construções residenciais precárias, muitas delas situadas em condições topográficas e de cobertura vegetal suscetíveis aos referidos eventos, em decorrência do elevado número de desabrigados e óbitos, os prejuízos acabam assumindo a proporção de desastre.

Em proporção inferior às enchentes e inundações, porém em número de ocorrências mais frequentes, os eventos relacionados aos deslizamentos de terras também têm somado prejuízos entre os municípios da RMM. Embora não existam informações disponíveis sobre o histórico de registros relacionados a deslizamento de terras entre os municípios metropolitanos, ao contrário das enchentes ou inundações bruscas que fazem parte do registro da imprensa local, sabe-se que as áreas mais suscetíveis (encostas) aos movimentos de massa estão degradadas ou irregularmente ocupadas por unidades habitacionais precárias. Por conseguinte, a vulnerabilidade às chuvas tem sido constante na realidade socioespacial das populações da RRM. 
Neste sentido, o objetivo do presente trabalho foi avaliar a opinião socioambiental da população residente nas principais cidades da RMM, em áreas vulneráveis aos eventos relacionados às chuvas intensas. Assim, considerando as múltiplas consequências associadas às chuvas intensas, os estudos orientados a análise de variáveis socioambientais capazes de estimar a percepção humana podem contribuir para o aprimoramento da gestão urbana, reduzindo as incertezas durante a tomada de decisão.

\section{Aspectos gerais da área de estudo}

Localizada na porção central do litoral alagoano, integram a RMM as cidades de Atalaia, Barra de Santo Antônio, Barra de São Miguel, Coqueiro Seco, Maceió, Marechal Deodoro, Messias, Murici, Paripueira, Pilar, Rio Largo, Santa Luzia do Norte e Satuba, conforme leis complementares 18, 38 e 40. Todavia, com exceção de Atalaia, os demais municípios que integram a referida RMM foi alvo do presente estudo. A exclusão da referida cidade advém da baixa frequência de eventos relacionados as chuvas intensas. Desta maneira, apesar da área total dos municípios analisados seja de aproximadamente $2.346,162 \mathrm{~km}^{2}$, os sítios urbanos consolidados estão muito aquém dessa realidade, com aproximadamente $156,961 \mathrm{~km}^{2}$; as suas respectivas sedes ocupam apenas $6,69 \%$ da extensão territorial da área de estudo.

Dentre as cidades que integram a RMM com sítios urbanos expressivos e em acanhado processo de conurbação à cidade de Maceió, destacam-se apenas Marechal Deodoro, Rio Largo e Satuba. O quadrante que engloba a área de estudo está localizado entre as latitudes

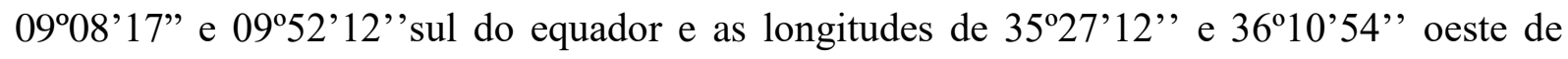
Greeenwich (Figura 1). Limita-se ao norte com os municípios de Branquinha, Flexeiras, Joaquim Gomes, Passo de Camaragibe, São Luís do Quitunde e União dos Palmares, ao sul com o município de Roteiro, ao leste com o Oceano Atlântico e ao oeste com os municípios de Atalaia, Boca da Mata Capela e São Miguel dos Campos. 
$\mathrm{EM}$

\section{QUESTÃO}

V.14 N. $01 \diamond 2021$

pág. 180-208

Figura 1 - Área de estudo: cidades da Região Metropolitana de Maceió, Alagoas, Brasil.

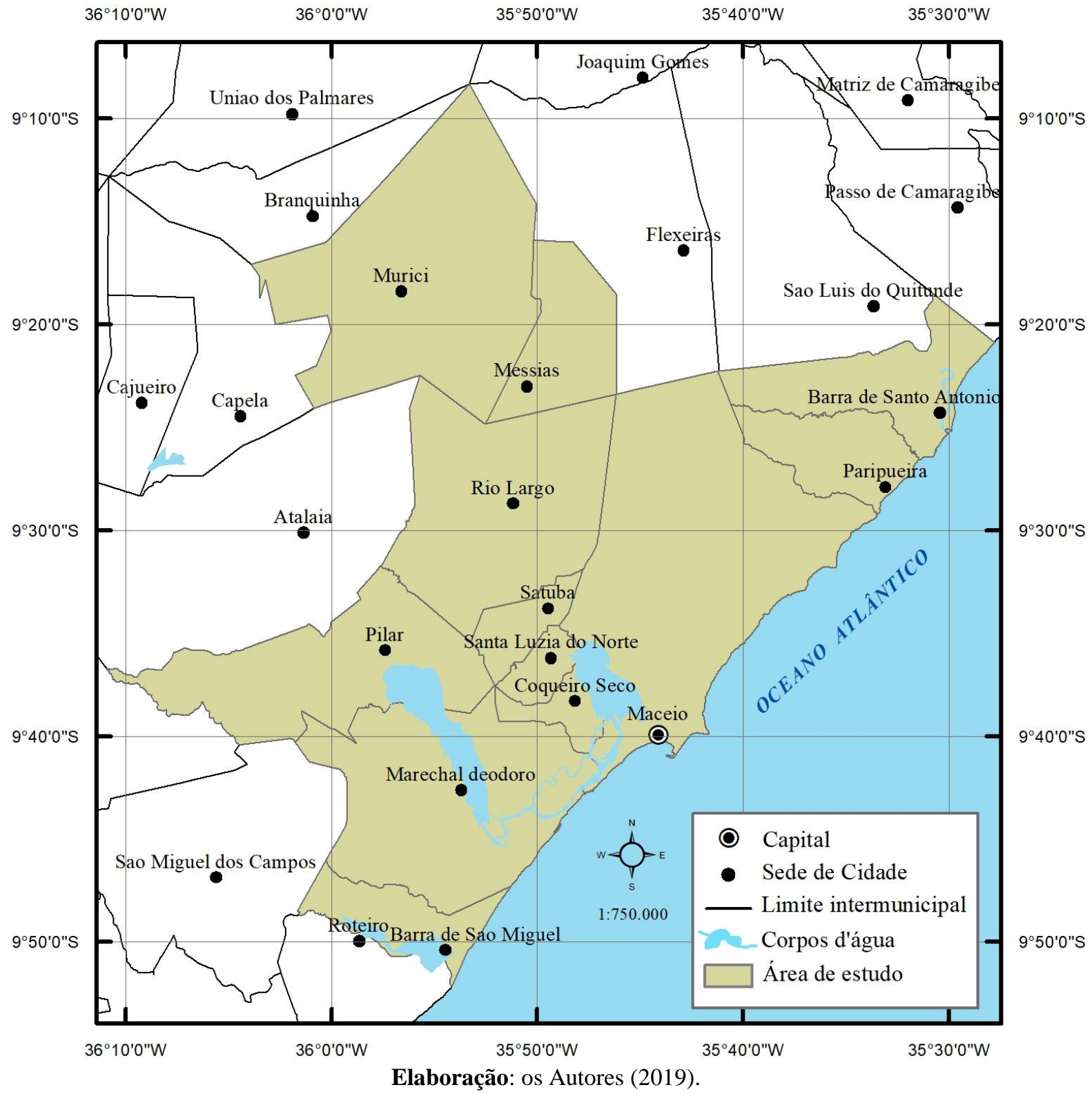

\section{Aspectos demográficos e socioeconômicos}

Considerando a realidade socioespacial das cidades nordestinas, as questões relacionadas aos extremos climáticos, consequentemente aos desastres e às condições de risco, devem ser tratadas com importância devida pelos gestores públicos locais. Na medida do possível, é preciso despertar a atenção para que as políticas públicas reforcem o debate sobre a organização, planejamento e gestão do território. 
EM

O crescimento populacional das áreas urbanizadas no estado de Alagoas contribuiu para que faixas de terras situadas em regiões vulneráveis às chuvas intensas fossem ocupadas de forma irregular. Assim sendo, analisando a Figura 2, é possível constatar que até a década de 1980 a maior parte da população alagoana estava concentrada na área rural. Ao longo do período observado, a população urbana superou a população rural a partir da década de 1990, registrando um efetivo de 1.481 .125 habitantes.

Figura 2 - Evolução das populações rural e urbana de Alagoas, entre 1940 a 2010.

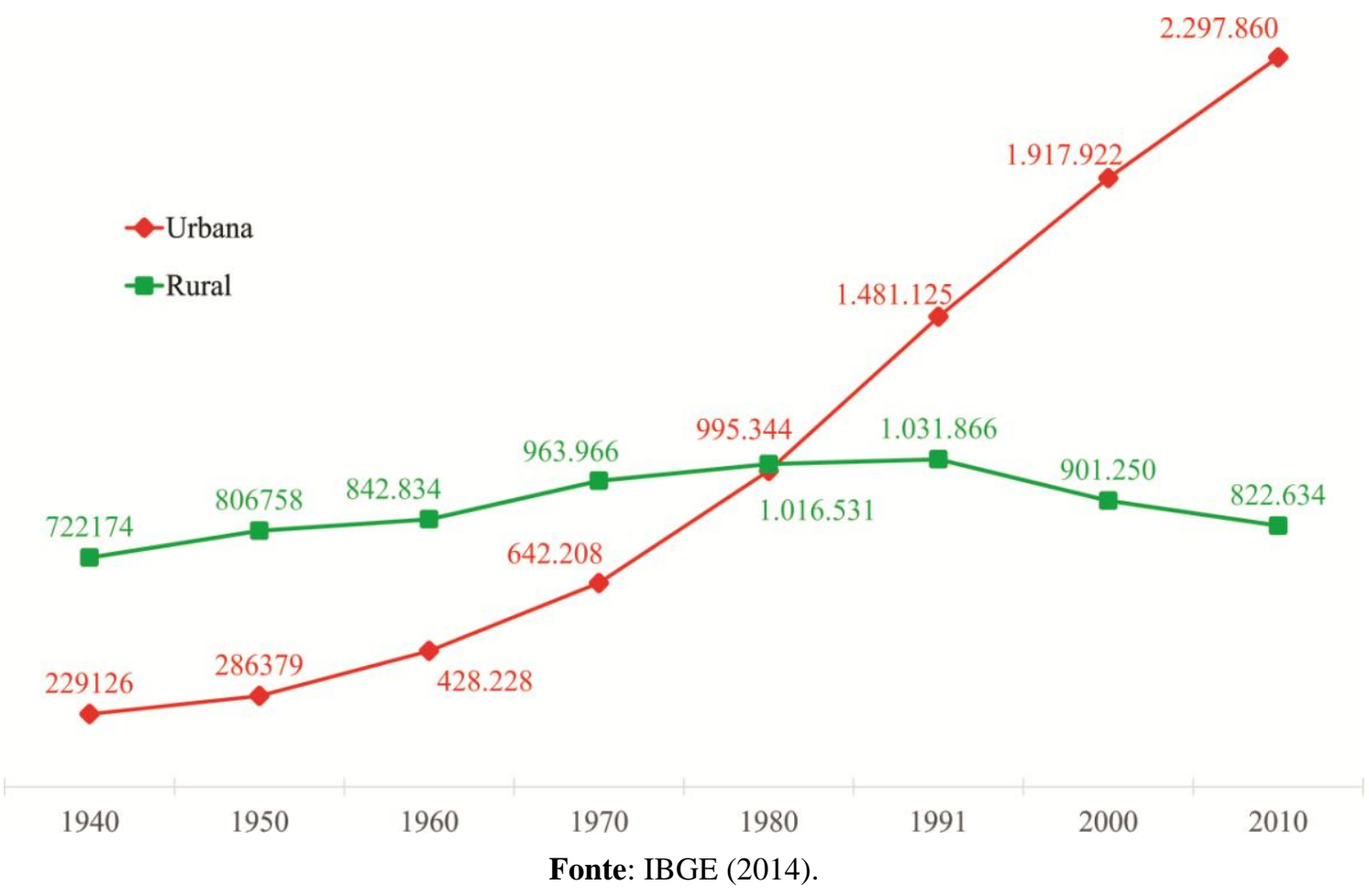

A partir da década de 1990, a maior parte dos municípios alagoanos passaram a concentrar os habitantes nas áreas urbanas. Embora as sedes dessas cidades oferecessem oportunidades de emprego e serviços públicos de saúde e educação, uma das razões que pode explicar a migração para as áreas urbanizadas tem relação com os períodos de estiagens prolongadas na região semiárida de Alagoas. As estiagens prolongadas têm sido o principal evento climático responsável pela movimentação dos habitantes nas regiões agreste e semiárido do estado de Alagoas, o que, muitas vezes, agrava as condições de vida das populações atingidas. De fato, o fenômeno da seca associado às ausências de assistência e planejamento social acabam obrigando as famílias a se deslocarem para as metrópoles, as quais, por sua vez, sem a infraestrutura adequada sofrem com a ocupação desordenada das áreas vulneráveis às chuvas intensas. 
EM

QUESTÃO

$\mathrm{V} .14 \bullet \mathrm{N} .01 \bullet 2021$

pág. 180-208

Atualmente o estado de Alagoas possui uma extensão de $27.778,506 \mathrm{~km}^{2}$ e uma população estimada pelo IBGE (2015) de 3.321 .730 habitantes. A densidade demográfica ainda continua fortemente concentrada na área de estudo, que reúne sozinha, aproximadamente 1.274 .622 habitantes, isto é, o equivalente a $38,37 \%$, da população total do estado. De acordo com IBGE (2011), desde o censo demográfico de 1940, a população urbana dos municípios que integram a área de estudo é superior à rural, conforme é possível observar na Figura 3.

Figura 3 - Evolução das populações rural e urbana da área de estudo, entre 1940 a 2010.

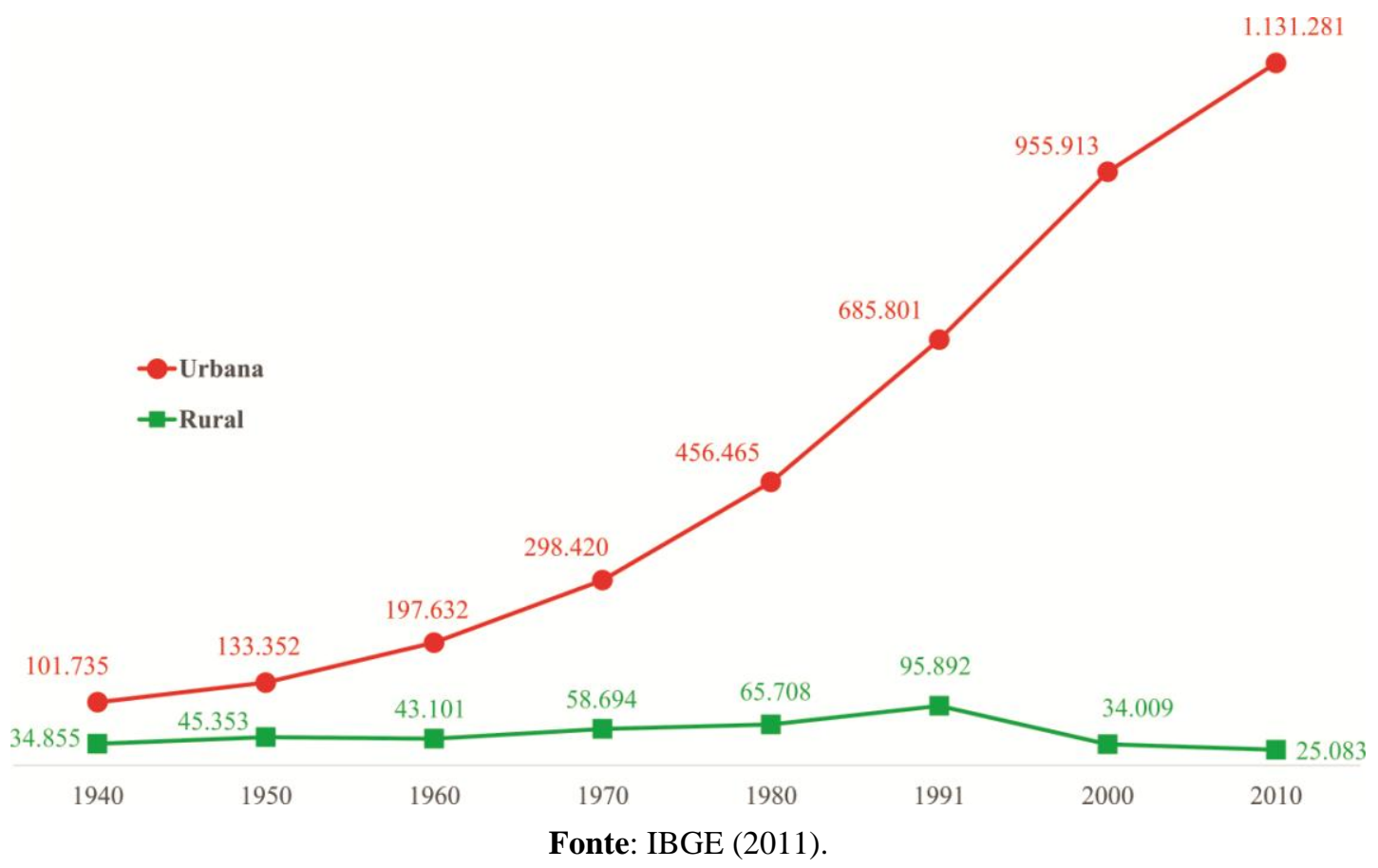

Ao se analisar a Figura 3, é possível verificar o aumento exponencial da população urbana da área de estudo, especialmente a partir da década de 1980, que registrou a maior taxa de crescimento de 52,96\% ao longo do período observado. Ao contrário da população urbana, o comportamento demográfico na área rural apresentou uma pequena variação, com um ligeiro decréscimo entre as décadas de 1950 e 1960, seguido de uma tendência de crescimento até a década de 1990 e retorno ao decréscimo nas duas décadas posteriores.

De acordo com o Censo Demográfico realizado pelo IBGE (2010), a área urbana do município de Maceió concentrava 82,39\% (932.129 habitantes) do total de habitantes residentes nos sítios urbanos pertencentes a conjunto de municípios que integram a área de estudo. Além da capital alagoana, também é possível verificar na Tabela 1 que os demais municípios possuíam população urbana superior à rural, com destaque para as cidades de 
EM

QUESTÃO

$\mathrm{V} .14 \downarrow \mathrm{N} .01 \bullet 2021$

pág. $180-208$

Marechal Deodoro, Pilar e Rio Largo que, sozinhas, são responsáveis por 11,59\% do total de habitantes residentes em áreas urbanas.

Tabela 1 - População residente, por situação do domicílio, na Área de Estudo, Alagoas, Brasil.

\begin{tabular}{|c|c|c|c|c|}
\hline \multirow{3}{*}{ Nome } & \multicolumn{4}{|c|}{ População Absoluta } \\
\hline & \multicolumn{3}{|c|}{2010} & 2019 \\
\hline & Rural & Urbano & Total & Estimada \\
\hline Barra de Santo Antônio & 988 & 13.242 & 14.230 & 15.932 \\
\hline Barra de São Miguel & 1.053 & 6.521 & 7.574 & 8.322 \\
\hline Coqueiro Seco & 553 & 4.973 & 5.526 & 5.845 \\
\hline Maceió & 619 & 932.129 & 932.748 & 1.018 .948 \\
\hline Marechal Deodoro & 2.585 & 43.392 & 45.977 & 51.901 \\
\hline Messias & 1.419 & 14.263 & 15.682 & 17.856 \\
\hline Murici & 4.602 & 22.108 & 26.710 & 28.236 \\
\hline Paripueira & 1.298 & 10.049 & 11.347 & 13.176 \\
\hline Pilar & 1.504 & 31.801 & 33.305 & 35.111 \\
\hline Rio Largo & 12.534 & 55.947 & 68.481 & 75.120 \\
\hline Santa Luzia do Norte & 719 & 6.172 & 6.891 & 7.296 \\
\hline Satuba & 1.811 & 12.792 & 14.603 & 13.828 \\
\hline Área de estudo & 25.083 & 1.131.281 & 1.156 .364 & 1.291.571 \\
\hline Estado de Alagoas & 822.634 & 2.297 .860 & 3.120 .494 & 3.337 .357 \\
\hline Nordeste & 14.258 .260 & 38.823 .690 & 53.081 .950 & 57.071 .654 \\
\hline
\end{tabular}

Fonte: Censo Demográfico, IBGE (2010); IBGE (2019).

Dessa maneira, pode-se dizer que a urbanização das cidades que integram a RMM, muitas vezes, tem sido precedida por um indiscriminado processo de ocupação. Esse fator associado à concentração de habitantes residentes nas encostas ou áreas sujeitas a enchentes e inundações tem causado diversos incidentes; a maioria deles resulta em prejuízos materiais e perdas de vidas humanas. A densidade demográfica $\left(492,87 \mathrm{hab} / \mathrm{km}^{2}\right)$ da RMM é consideravelmente superior aos valores encontrados para o estado de Alagoas e região nordeste. Com exceção da Barra de Santo Antônio, Barra de São Miguel e Murici, os demais municípios da RMM possuem densidade demográfica superior ao estado de Alagoas, com destaque para a cidade de Maceió que possui $1.854,12 \mathrm{hab} / \mathrm{km}^{2}$.

Nesse contexto, as condições socioeconômicas da população da RMM têm sido predominantemente marcadas por diferenças acentuadas em relação à distribuição da riqueza produzida pelos setores produtivos que atuam na referida região, consequentemente na qualidade de vida dos seus habitantes. Embora a RMM disponha de uma razoável infraestrutura, reunindo a sede do governo do estado de Alagoas e um conjugado sistema de acessos aéreo, marítimo e terrestre, o seu crescimento econômico tem sido relativamente doi.org/10.48075/geoq.v14i1.24496 
EM

QUESTÃO

$\mathrm{V} .14 \bullet \mathrm{N} .01 \bullet 2021$

pág. 180-208

tímido quando comparado àquele alcançado pelas principais regiões metropolitanas do nordeste brasileiro.

Pela observação da Tabela 2, é possível verificar que a RMM possui o menor Índice de Desenvolvimento Humano - $\mathrm{IDH}^{4}$, inclusive entre as regiões metropolitanas que obtiveram Produto Interno Bruto - PIB nominal inferior a ela. Para Costa (2007, p. 6), a renda per capita como indicador não é suficiente, uma vez que não averigua os males da má distribuição da renda ou mesmo sobre a educação, longevidade e renda. Por essa razão, os indicadores sociais como IDH são mais apropriados quando se deseja revelar disparidades na distribuição das riquezas produzidas.

Por se considerar o IDH uma medida resumida do nível de desenvolvimento humano relacionada às dimensões básicas de saúde, educação e renda, a sua utilização nas avaliações do desempenho da gestão pública tem contribuído para otimizar os investimentos e reduzir as incertezas sobre a implementação das políticas sociais. Embora o IDH da RMM em 2010 tenha sido igual a 0,724 , ou seja, considerado alto desenvolvimento humano, ao se analisar isoladamente os municípios que integram a referida área de estudo, percebe-se que 6 (seis) dos 12 (doze) municípios, isto é, a metade, são classificados com médio desenvolvimento humano (IDH-M entre 0,600 a 0,699).

Tabela 2 - Produto Interno Bruto - PIB nominal e Índice de Desenvolvimento Humano - IDH das principais regiões metropolitanas do nordeste brasileiro.

\begin{tabular}{l|c|c|c}
\hline \multicolumn{1}{c|}{ Região Metropolitana } & $\begin{array}{c}\text { PIB nominal (2011) } \\
\text { bilhão }\end{array}$ & PIB Per capita & IDH (2010) \\
\hline Salvador & 72,198 & 21149,60 & 0,794 \\
Recife & 67,219 & 18081,28 & 0,780 \\
Fortaleza & 57,753 & $16.300,09$ & 0,767 \\
São Luís & 21,971 & $17.607,20$ & 0,766 \\
Natal & 18,506 & 9700,95 & 0,762 \\
João Pessoa & 17,305 & $12.671,36$ & 0,746 \\
Maceió & 15,862 & $9.389,71$ & 0,724 \\
Teresina & 13,216 & $7.794,74$ & 0,751 \\
Aracaju & 12,220 & $10.900,00$ & 0,763 \\
\hline
\end{tabular}

Fonte: IBGE (2014) e PNUD (2013).

Pela análise da Tabela 3, é possível verificar que ao longo das últimas três décadas os municípios inseridos na área de estudo promoveram mudanças em suas políticas sociais as quais repercutiram sobremaneira nos indicadores de desenvolvimento de humano, que passaram de

\footnotetext{
${ }^{4}$ Muito alto desenvolvimento humano (0,800 a 1); Alto desenvolvimento humano (0,700 a 0,799); Médio desenvolvimento humano $(0,600$ a 0,699$)$; Baixo desenvolvimento humano $(0,500$ a 0,599$)$; e Muito baixo desenvolvimento humano $(0$ a 0,499$)$.
} 
EM

QUESTÃO

V.14 N. $01 \bullet 2021$

pág. $180-208$

muito baixo ou baixo para médio ou alto. Dentre aqueles com médio desenvolvimento humano (IDH-M entre 0,600 a 0,699), destacam-se os municípios de Satuba, Rio Largo e Marechal Deodoro, respectivamente, com IDH-M equivalentes a 0,660, 0,643 e 0,642.

Tabela 3 - Evolução do IDH na RMM ao longo das décadas de 1991, 2000 e 2010.

\begin{tabular}{l|c|c|c}
\hline \multicolumn{1}{c}{ Denominação } & \multicolumn{3}{c}{ IDH-M } \\
\cline { 2 - 4 } & 1991 & 2000 & 2010 \\
\hline Barra de São Miguel & 0,275 & 0,440 & 0,615 \\
Barra de Santo Antônio & 0,265 & 0,378 & 0,557 \\
Coqueiro Seco & 0,344 & 0,466 & 0,586 \\
Maceió & 0,507 & 0,584 & 0,721 \\
Marechal Deodoro & 0,349 & 0,463 & 0,642 \\
Messias & 0,306 & 0,379 & 0,568 \\
Murici & 0,273 & 0,391 & 0,527 \\
Paripueira & 0,312 & 0,423 & 0,605 \\
Pilar & 0,325 & 0,418 & 0,610 \\
Rio Largo & 0,389 & 0,505 & 0,643 \\
Santa Luzia do Norte & 0,375 & 0,434 & 0,597 \\
Satuba & 0,416 & 0,543 & 0,660 \\
Área de estudo (IDH) & - & $\mathbf{0 , 6 9 0}$ & $\mathbf{0 , 7 2 4}$ \\
Estado de Alagoas (IDH) & $\mathbf{0 , 5 2 7}$ & $\mathbf{0 , 5 7 4}$ & $\mathbf{0 , 6 3 1}$ \\
\hline
\end{tabular}

Fonte: PNUD (2013).

Embora a maioria dos municípios tenha IDH-M entre médio e alto desenvolvimento humano e social, a avaliação específica do desempenho da educação mostra que apenas o município de Maceió não possui IDH-Educação inferior 0,599, isto é, entre baixo e muito baixo desenvolvimento humano e social (Tabela 4). Tendo em vista o papel da educação como um indicador estratégico capaz de influenciar o desempenho social e econômico de uma sociedade, a área de estudo apresenta uma considerável limitação quanto à qualidade de vida dos seus habitantes. Barros e Mendonça (1997, p. 1) asseveram que os investimentos em educação tendem a elevar os salários via aumentos de produtividade, a aumentar a expectativa de vida com a eficiência com que os recursos familiares existentes são utilizados, o que reduz, portanto, o grau de pobreza futuro.

Portanto, os indicadores de desenvolvimento humano relativos à educação e às condições de infraestrutura de saneamento público são fundamentais para o sucesso dos planos de gestão urbana, especialmente aqueles relacionados aos problemas decorrentes dos eventos climáticos extremos. A Organização Mundial de Saúde - OMS considera o saneamento básico como uma das principais intervenções para o controle de todos os fatores do meio físico do homem que exercem ou podem exercer efeito prejudicial ao seu bem-estar físico, mental ou social. Barros et al (1995) destacam ainda que as condições de saneamento 
EM

QUESTÃO

V.14 N. $01 \bullet 2021$

pág. 180-208

básico ideais estão associadas, entre outros serviços, a uma infraestrutura construída de coleta de águas pluviais e de controle de empoçamentos e inundações.

Tabela 4 - Índice de Desenvolvimento Humano de renda, educação e saúde da Área de estudo, Alagoas, Brasil.

\begin{tabular}{l|c|c|c}
\hline \multirow{2}{*}{ Nome } & \multicolumn{3}{c}{ IDH-M (2010) } \\
\cline { 2 - 4 } & Renda & Longevidade & Educação \\
\hline Barra de São Miguel & 0,638 & 0,767 & 0,475 \\
Barra de Santo Antônio & 0,552 & 0,732 & 0,428 \\
Coqueiro Seco & 0,582 & 0,757 & 0,457 \\
Maceió & 0,739 & 0,799 & 0,635 \\
Marechal Deodoro & 0,641 & 0,793 & 0,520 \\
Messias & 0,557 & 0,714 & 0,460 \\
Murici & 0,542 & 0,685 & 0,395 \\
Paripueira & 0,595 & 0,767 & 0,486 \\
Pilar & 0,578 & 0,771 & 0,509 \\
Rio Largo & 0,616 & 0,788 & 0,547 \\
Santa Luzia do Norte & 0,580 & 0,770 & 0,477 \\
Satuba & 0,619 & 0,794 & 0,585 \\
Alagoas & $\mathbf{0 , 6 4 1}$ & $\mathbf{0 , 7 5 5}$ & $\mathbf{0 , 5 2 0}$ \\
Brasil & $\mathbf{0 , 7 3 9}$ & $\mathbf{0 , 8 1 6}$ & $\mathbf{0 , 6 3 7}$ \\
\hline
\end{tabular}

Fonte: PNUD (2013).

Como já mencionado anteriormente, as condições de vulnerabilidade socioambiental da RMM às chuvas intensas, entre outros fatores, estão associadas ao processo inadequado de ocupação e o uso intensivo da terra. Embora a estiagem/seca seja o evento climático de maior abrangência e mais recorrente no estado de Alagoas, as ocorrências na área de estudo estão majoritariamente relacionadas aos eventos influenciados pela dinâmica pluviométrica, na qual predominam os problemas de alagamentos, deslizamentos, enchentes e inundações.

Além das ocorrências de chuvas que deflagram esses tipos de eventos, os municípios que integram a RMM reúnem o maior número de aglomerados subnormais (favelas) do estado de Alagoas. Os últimos mapeamentos realizados pelo IBGE (2010) indicam que a referida área de estudo concentra 94,6\% das aglomerações subnormais mapeadas, que foram 129 localidades em todo território alagoano. A maioria dessas favelas está situada nas encostas ou áreas sob influência do regime de cheias dos rios e lagunas. Os habitantes dessas localidades estão em condições extremas sob o ponto de vista social; muitas vezes situados abaixo da linha da pobreza, acabam construindo as suas moradias em condições precárias, potencializando ainda mais o nível de vulnerabilidade socioambiental, por conseguinte as condições de riscos. 
No histórico de perturbação das cidades alvo do presente estudo, foram verificadas ocorrências relacionadas a inundações/enchentes e deslizamentos de terra, sendo a maioria desses eventos decorrentes das chuvas. Embora os alagamentos também façam parte da realidade da referida área de estudo, a ocorrência desse tipo de evento está fortemente associada à deficiência no sistema de drenagem de águas pluviais e à deposição inadequada dos rejeitos (lixo) domésticos.

Os desmoronamentos de casas nas áreas de encostas têm sido os problemas mais recorrentes nas cidades litorâneas da Barra de Santo Antônio, Barra de São Miguel, Maceió e Paripueira. Já os problemas de enchentes/inundações têm atingido de maneira incisiva as populações dos municípios de Coqueiro Seco, Marechal Deodoro, Murici, Rio Largo, Pilar, Santa Luzia do Norte e Satuba.

De maneira geral, a área de estudo sofre com os diversos problemas decorrentes das precipitações pluviométricas intensas, seja pela ausência de planejamento adequado ou devido às restritas condições operacionais dos diferentes órgãos de gestão e controle, por exemplo, as coordenadorias municipais de defesa civil.

\section{Procedimentos metodológicos}

A pesquisa foi realizada por meio de levantamento de campo e teve como finalidade verificar de maneira amostral a opinião da população sobre os problemas socioambientais decorrentes das chuvas intensas em municípios pertencentes a região metropolitana. Para tanto, foram realizadas entrevistas com auxílio de instrumento de coleta de informações (questionário), que foi subdividido em três blocos (Quadro 1). Gil (2008) e Nogueira (2009) destacam que a adoção de questionário tem sido bastante utilizada em diversas atividades científicas, em particular, nas Ciências Sociais, inclusive como instrumento direcionado à investigação, ao diagnóstico e à orientação. Embora um questionário, por mais cuidadosamente elaborado que seja, não esgota todos os aspectos de uma dada realidade (MARANGONI, 2009, p. 170), cabe salientar que, as repercussões socioambientais decorrentes dos eventos relacionadas às chuvas intensas na RMM alcançam dimensões além dos limites definidos nos ensaios e levantamentos de campo discutidos a seguir.

O universo amostral selecionado considerou a população residente nos setores censitários delimitados por Nascimento (2016) com muito baixa, baixa, média, alta e muito alta 
vulnerabilidades socioambientais. No entanto, embora essas áreas possuam um efetivo populacional importante, mas, sob a perspectiva da avaliação da opinião socioambiental da população, optou-se preferencialmente pelas comunidades inseridas nas faixas de média, alta e muito alta vulnerabilidades socioambientais, bem como pelas localidades já consideradas de riscos pelas defesas civis municipais. Tal fato advém da certeza de que a maioria dos moradores dessas localidades é legitimamente qualificada por possuir em seus históricos de vida, experiências incontestáveis sobre os eventos relacionados às chuvas intensas na área analisada.

A partir do referido critério, foi identificada a população do setor censitário correspondente e definiu-se o tamanho da amostra para um nível de significância de $96 \%$. Tendo em vista o número total de habitantes nos setores censitários que integram a área de estudo, foi calculado o tamanho da amostra, em que, $\boldsymbol{n}_{\mathbf{0}}$ corresponde a primeira aproximação do tamanho da amostra; $\boldsymbol{E}_{\mathbf{0}}$ ao erro amostral tolerável; $\mathbf{N}$ ao número de elementos da população; e $\mathbf{n}$ ao tamanho da amostra, conforme equações a seguir:

$$
n_{0}=\frac{1}{E_{0}^{2}} \quad n=\frac{N \cdot n_{0}}{N+n_{0}}
$$

Com o objetivo de aferir a opinião da população sobre os problemas socioambientais, entre outros fatores, relacionados às chuvas intensas, admitiu-se um erro amostral de 0,04 $(4,00 \%)$ a fim de obter o tamanho da amostra para aplicação dos questionários, que correspondeu a um total de 625 amostras. Posteriormente, foi elaborado um roteiro de entrevista experimental, que teve como finalidade verificar a funcionalidade do questionário e avaliar a necessidade de eventuais correções. Inicialmente foram aplicados 25 questionários de forma aleatória com o objetivo de se verificar o grau de dificuldade do entrevistador quanto à formulação das perguntas e a facilidade do entrevistado em respondê-las. A definição dos setores censitários, bairros e logradouros alvos da coleta de dados, ou seja, destinados à aplicação dos questionários foi aleatória. Após a aplicação dos questionários destinados à investigação da opinião da população sobre os problemas socioambientais existentes na área de estudo, os resultados foram sistematizados, de modo a se observar a ocorrência de respostas inconsistentes. Os dados foram classificados e organizados para otimizar a capacidade de análise e apresentação em formatos de fácil compreensão, como gráficos e tabelas. Assim sendo, a conjugação de todas as informações gráficas e tabelas tornaram possíveis a análise sistêmica e o alcance holístico dos aspectos mais representativos da paisagem urbana dos municípios alvo do estudo. 
Quadro 1 - Demonstrativo das questões empregadas no instrumento de coleta da pesquisa.

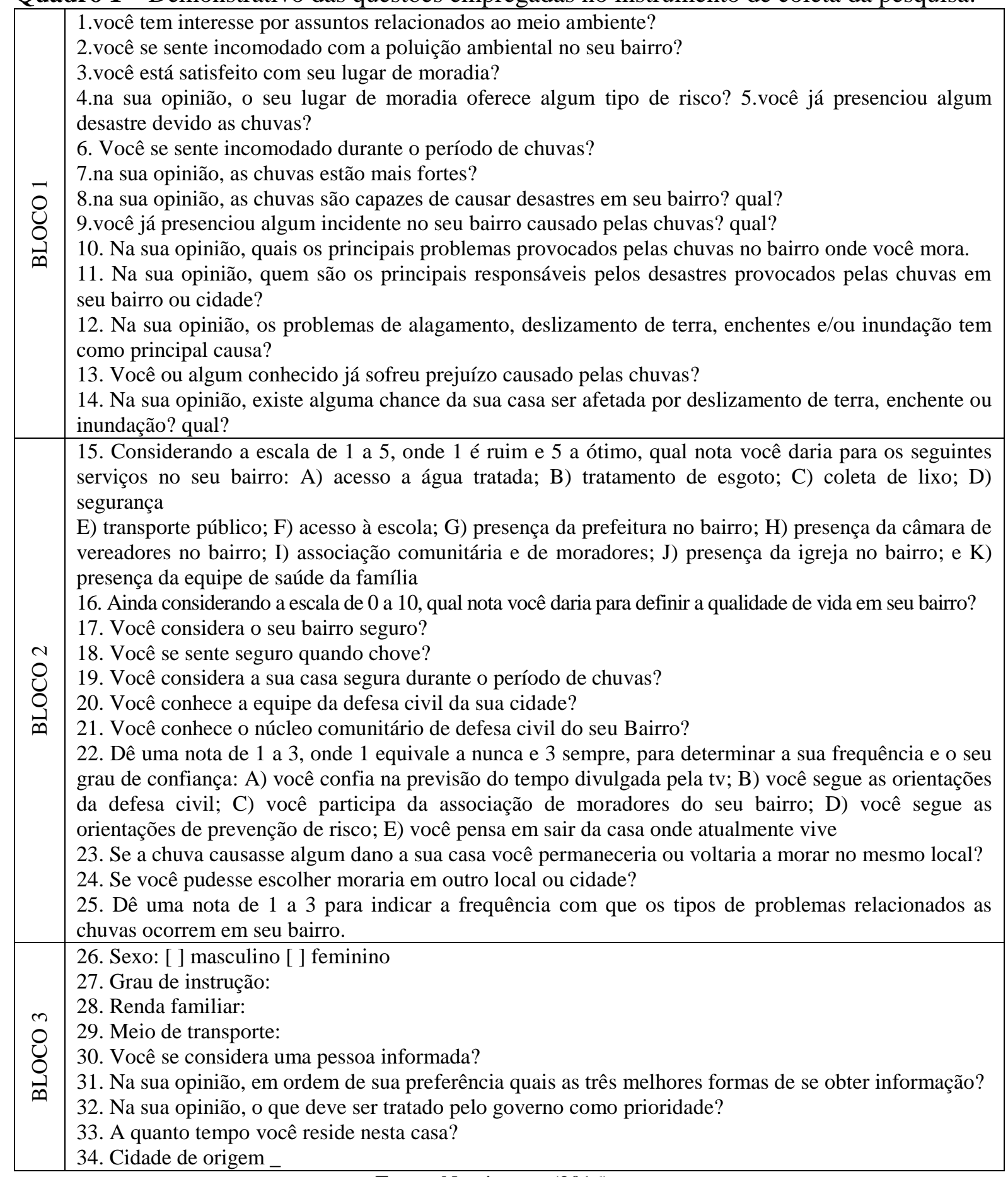

Fonte: Nascimento (2016).

\section{Resultados e discussões}

Os resultados obtidos no presente estudo tiveram como finalidade avaliar a opinião socioambiental dos habitantes residentes em áreas vulneráveis aos eventos relacionados às chuvas intensas. Assim sendo, considerando-se os procedimentos metodológicos 
EM

QUESTÃO

V.14 N. $01 \bullet 2021$

pág. 180-208

anteriormente descritos, o número de questionários relativo ao erro amostral tolerável adotado, o quantitativo amostral pode ser interpretado como uma fração da população; por essa razão, deve-se admitir ao longo de toda a análise uma margem de erro equivalente a mais ou menos ( \pm ) 4,00\% para um grau de confiança de $96 \%$.

Observando a Tabela 5 é possível verificar a distribuição quantitativa de amostras aplicadas entre os municípios que integram a área de estudo. É preciso esclarecer que o quantitativo de questionários definidos para cada município baseou-se no histórico de ocorrências já registradas pela defesa civil durante os períodos de chuva, bem como pelo grau de adensamento populacional de cada cidade. As cidades de Maceió (48,21\%), Marechal Deodoro $(9,74 \%)$ e Rio Largo (11,20\%), por possuírem o maior contingente populacional da RMM, representam juntas aproximadamente $69,60 \%$ do efetivo total da amostra, isto é, a maioria dos questionários aplicados.

Tabela 5 - Distribuição quantitativa de amostras por municípios.

\begin{tabular}{c|l|c|c|c|c}
\hline \multirow{2}{*}{$\mathbf{N}^{\mathbf{2}}$} & \multicolumn{2}{c|}{ Município } & \multicolumn{2}{c|}{ População } & \multicolumn{2}{c}{$\begin{array}{c}\text { Amostra } \\
\text { (No de questionários aplicados) }\end{array}$} \\
\cline { 3 - 6 } & & absoluto & \% & absoluto & \% \\
\hline 1 & Barra de Santo Antônio & 14.104 & 1,20 & 23 & 3,68 \\
2 & Barra de São Miguel & 7.421 & 0,63 & 12 & 1,92 \\
3 & Coqueiro Seco & 5.516 & 0,47 & 21 & 3,36 \\
4 & Maceió & 929.143 & 79,03 & 306 & 48,96 \\
5 & Marechal Deodoro & 45.552 & 3,87 & 60 & 9,60 \\
6 & Messias & 15.429 & 1,31 & 19 & 3,04 \\
7 & Murici & 24.787 & 2,11 & 32 & 5,12 \\
8 & Paripueira & 11.290 & 0,96 & 22 & 3,52 \\
9 & Pilar & 33.263 & 2,83 & 30 & 4,80 \\
10 & Rio Largo & 67.629 & 5,75 & 69 & 11,04 \\
11 & Santa Luzia do Norte & 6.873 & 0,58 & 17 & 2,72 \\
12 & Satuba & 14.603 & 1,24 & 14 & 2,24 \\
\hline & TOTAL & $\mathbf{1 . 1 7 5 . 6 1 0}$ & $\mathbf{1 0 0 , 0 0}$ & $\mathbf{6 2 5}$ & $\mathbf{1 0 0 , 0 0}$ \\
\hline
\end{tabular}

Organização: os Autores.

No que se refere às localidades selecionadas para a coleta das amostras, isto é, para aplicação dos questionários, conforme já mencionado, adotou-se como critério o nível de vulnerabilidade socioambiental. Assim sendo, os questionários foram distribuídos entre 79 setores censitários pertencentes aos municípios que integram a área de estudo, tendo a cidade de Maceió concentrado a maior parte dos setores censitários (44,30\%), enquanto o município da Barra de São Miguel ficou restrito a um setor censitário. 
A partir das entrevistas realizadas a uma parcela da população residente na área de estudo, bem como pelos levantamentos realizados junto às equipes de defesa civil, foi possível apresentar os resultados a seguir. Cabe ressaltar que, embora tais resultados sejam indicativos amostrais da opinião socioambiental da população, eles são capazes de revelar os sentimentos predominantes entre os habitantes das comunidades vulneráveis às chuvas intensas, especialmente aquelas alvo das ocorrências de deslizamento de terra e enchente/inundação.

Perfil da população entrevistada

Pela observação de aspectos como gênero, idade, grau de instrução, renda familiar, meio de transporte e interesse por assuntos de utilidade pública, foi possível constatar que a população entrevistada possui um perfil relativamente homogêneo, sendo a maior parte com ensino fundamental incompleto, renda familiar correspondente até a um salário mínimo e uma considerável predileção pela saúde como assunto de interesse prioritário.

A maioria da população analisada é de mulheres $(61,76 \%)$; destas, em torno de $75,20 \%$ possuem média de idade superior aos 30 anos, e um pouco mais da metade $(50,24 \%)$ idade acima dos 40 anos. Ao se considerar que o conhecimento dos eventos associados às chuvas intensas na área de estudo pelos seus habitantes, entre outros fatores, depende da experiência vivenciada por eles. Assim, verificou-se que 47,27\% dos entrevistados declararam residir há mais de 10 (dez) anos na mesma comunidade. Se admitido que a maior parte dos habitantes da área de estudo, especificamente, dos municípios de Rio Largo e Murici, testemunhou, no início da década de 2010, um dos mais traumáticos episódios de enchente, pode-se considerar que a amostra coletada foi relativamente representativa sob o ponto de vista sociocultural, pois em torno de $61,99 \%$ residem há mais de 5 anos em suas localidades.

Para o nível de escolaridade, foram considerados com baixo grau de alfabetização os entrevistados cujos hábitos de leitura e escrita são bastante restritos, sendo estes os que declararam possuir o nível de escolaridade inferior ao ensino fundamental incompleto. Observou-se que aproximadamente $62,40 \%$ estão inseridos nesse contexto, tendo a maior parte dos entrevistados o ensino fundamental incompleto (45,83\%). Do total de entrevistados, uma parcela correspondente a 19,36\% declarou-se analfabeta, e apenas 2,08 concluíram o ensino superior. É possível que a quantidade reduzida de pessoas entrevistadas com formação superior seja uma infeliz coincidência, mas foi possível observar durante a aplicação dos 
questionários que as localidades visitadas se encontram socialmente alijadas do consumo e da participação econômica, muitas vezes, reféns de programas sociais.

Os municípios de Maceió e Marechal Deodoro registraram a maior quantidade de entrevistados com formação superior. Tal fato evidencia ainda mais a pouca incidência de pessoas com esse perfil nas demais localidades visitadas. Embora o baixo grau de escolaridade já seja um indicador negativo para o desenvolvimento dessas comunidades, a situação torna-se ainda mais acentuada quando verificam-se os resultados sobre a renda familiar. Do total de entrevistados, em torno de $70,88 \%$ possuem renda igual ou inferior a 1 salário mínimo. Em torno de 48,16\%\% dos entrevistados sobrevivem com uma renda mensal de 1 salário mínimo.

Já os entrevistados que declararam possuir renda familiar inferior a 1 salário mínimo representam 22,72\% da amostra. Provavelmente, a parcela da população com renda inferior a 1 salário mínimo atue na informalidade, ou seja, beneficiada por algum programa social do governo federal (bolsa família, bolsa escola, dentre outros). Essas limitadas condições de renda familiar associadas ao baixo nível de instrução asseveram ainda mais a vulnerabilidade socioambiental dos municípios que integram a RMM.

Outro aspecto relevante sobre o perfil da população entrevistada consiste na forma de acesso à informação. Nessa perspectiva sociocultural, os avanços tecnológicos seguidos da presença da internet no cotidiano das pessoas têm desempenhado um papel decisivo. No entanto, apesar da presente década ser marcada pela popularização das tecnologias digitais de acesso rápido à informação (smartphones, notebooks e tablets), ainda assim, uma parcela de $67,81 \%$ dos entrevistados declarou não ser pessoa informada.

Nesse contexto de similaridades e discrepâncias quanto ao acesso à informação, segundo a população entrevistada, as três melhores formas de se obter informação têm sido através da TV $(34,94 \%)$, Jornal $(14,61 \%)$ e pela Internet $(14,16 \%)$.

Quanto ao assunto de maior interesse entre os entrevistados, isto é, aquele que deveria ser tratado como prioridade pelo Governo, em torno de 54,72\% dos entrevistados indicaram a saúde como assunto de interesse prioritário, seguido da educação $(11,68 \%)$, emprego $(9,76 \%)$ e da segurança pública $(8,00 \%)$, considerados os assuntos de interesse nas demais posições na escala de prioridade da população entrevistada.

Ao contrário dos demais assuntos, a temática ambiental encontra-se aparentemente preterida pela maioria da população da área de estudo. Isso não significa que há desinteresse 
pelo tema, mas com $1,76 \%$ das indicações o assunto meio ambiente ocupou a última posição no ideário de vida dos entrevistados como prioridade para pauta governamental.

A opinião da população entrevistada sobre os problemas socioambientais

De maneira geral, os resultados indicam que apesar das diferenças entre o grau de instrução e a opinião sobre assuntos relacionados à cidadania e ao meio ambiente, a população pertencente à área de estudo possui clarividência suficiente para avaliar as condições socioambientais na qual está inserida. Assim sendo, com base nas entrevistas realizadas, foi possível verificar que, apesar de ter sido eleito como assunto menos prioritário, o tema meio ambiente teve $75,52 \%$ de aceitação e o incômodo com a poluição ambiental representou $79,36 \%$ do universo da amostra. Esses resultados sugerem que uma parcela significativa dos moradores pode ser sensível à implantação de programas de educação ambiental. Embora a insatisfação dos entrevistados com o seu lugar de moradia tenha sido correspondente a $36,80 \%$ da amostra, a maior parte acredita que a casa onde reside oferece algum tipo de risco $(58,72 \%)$ e que aproximadamente $64,00 \%$ da população entrevistada já presenciou algum tipo de desastre causado pelas chuvas.

No entanto, apesar de $2 / 3(66,40 \%)$ do universo amostral admitir que as chuvas são capazes de causar algum tipo de desastre em sua comunidade, um pouco mais da metade $(50,56 \%)$ não se sente incomodada durante o período chuvoso. Cabe salientar que os setores censitários selecionados nesta etapa da pesquisa são visivelmente vulneráveis durante os meses de chuvas, especialmente quanto às ocorrências de deslizamento de terra, enchentes e inundações.

Diante desse fato, aproximadamente $88,39 \%$ dos entrevistados reconhecem que em suas localidades durante o período chuvoso é possível ocorrer algum problema relacionado ao deslizamento de terra, enchente, inundação ou alagamento de rua. Deste total, a maior parte considerou o deslizamento de terra $(35,04 \%)$ e o alagamento de rua $(23,62 \%)$ os problemas mais comuns em seus bairros ou cidade. As manifestações indicando os problemas relacionados às enchentes $(17,32 \%)$ e inundações $(12,41 \%)$ representaram juntas $29,73 \%$ dos entrevistados.

A população entrevistada de oito cidades da RMM (Barra de Santo Antônio, Barra de São Miguel, Coqueiro Seco, Maceió, Messias, Paripueira, Pilar e Rio Largo) considera o deslizamento de terra como principal problema causado pelas chuvas; duas cidades (Marechal 
EM

QUESTÃO

V.14 N. $01 \bullet 2021$

pág. 180-208

Deodoro e Murici) reconhecem como principal problema as enchentes; e nas demais cidades (Santa Luzia do Norte e Satuba), os entrevistados declararam as ocorrências de alagamento de rua como principal problema decorrente das chuvas.

Os eventos relacionados às chuvas intensas assumem proporções variadas entre os municípios que integram a RMM, bem como entre as vilas, bairros e logradouros de uma mesma cidade. No entanto, embora não exista um consenso sobre qual tipo de problema pode ocorrer em decorrência das chuvas, a maioria absoluta dos entrevistados considera que o Governo $(44,71 \%)$ e a População em geral $(42,89 \%)$ são os principais responsáveis pelos desastres ocorridos durante as chuvas. Na opinião de mais de 2/3 dos entrevistados, a presença da Prefeitura e da Câmara de Vereadores em seus bairros foi considerada Ruim. Os levantamentos indicaram que o desempenho local dos aludidos segmentos políticos foi considerado insuficiente pela população entrevistada, sendo respectivamente $78,72 \%$ e $86,24 \%$ negativamente avaliados. Essa sensação de abandono se revela de forma mais evidente quando a população é inquirida sobre a qualidade dos serviços de saúde e segurança pública. Os levantamentos também indicam que aproximadamente 70,56\% dos entrevistados consideraram Ruim o tratamento dado ao esgoto em seus bairros e que cerca de $46,72 \%$ qualificaram o acesso à água tratada como Regular ou Ruim.

A ineficiência do serviço de coleta de lixo pode se tornar um grande problema de saúde pública, especialmente nos períodos de chuvas. Considerando-se que o alagamento de rua está associado à deficiência no sistema de drenagem urbana, muitas vezes, devido a obstrução das galerias de águas pluviais, a opinião da população sobre a coleta de lixo em suas comunidades permitiu avaliar um item importante da qualidade de vida e verificar, sob o ponto de vista antropogênico, o quanto as condições locais podem ser favoráveis para ocorrência dessa modalidade de problema durante as chuvas. Embora uma parcela acanhada dos entrevistados $(11,68 \%)$ tenha considerado o serviço de coleta de lixo Ótimo, observou-se que $46,82 \%$ consideraram Regular ou Ruim.

O presente estudo de avaliação da opinião socioambiental aos problemas decorrentes das chuvas na RMM foi capaz de revelar a opinião dos entrevistados em relação a diversos assuntos, além de discutir as preferências e ideias predominantes entre os diversos grupos sociais. Pode-se dizer que os resultados obtidos são "verdades" circunstanciais, por conseguinte, perfeitamente mutáveis. Assim sendo, verificou-se que em torno de $91,52 \%$ da população entrevistada não conhece a equipe da Defesa Civil das cidades que integram a RMM. Dentre algumas explicações capazes de esclarecer o referido resultado, pode-se 
destacar a ineficiência nas estratégias de comunicação e publicização adotadas pelo gestor municipal, bem como a confusão devido ao fato de os integrantes da defesa civil desempenharem na própria administração municipal múltiplas funções.

A atuação das associações comunitárias e de moradores pode desempenhar um papel relevante na organização social de uma comunidade, especialmente quando do engajamento dessas entidades nos núcleos de defesa civil. Infelizmente a maioria dos entrevistados $(78,72 \%)$ classificaram como Ruim a presença das associações comunitárias e de moradores. Os resultados indicaram que a população das localidades visitadas atua muito pouco nas associações comunitárias dos seus bairros. De acordo com os levantamentos realizados, constatou-se que apenas 4,00\% dos entrevistados participam das atividades e reuniões promovidas por essas entidades. Ao contrário disso, em torno de 75,68\% dos entrevistados avaliaram como Bom e Ótimo o envolvimento das instituições religiosas em seus bairros.

Uma perspectiva sobre a vulnerabilidade socioambiental aos eventos relacionados às chuvas intensas

São vários os fatores que influenciam o relacionamento do indivíduo com o meio ambiente e a sociedade nos quais ele está inserido. O aspecto cultural é, sem dúvida, um dos mais importantes deles, tendo em vista o seu papel contributivo para a concepção da percepção humana. Diante desse contexto, a avaliação envolvendo alguns dos aspectos humanos da sociedade, sobretudo aqueles relacionados ao cotidiano do indivíduo, buscou identificar por meio da opinião socioambiental da população entrevistada os fatores antropogênicos capazes de influenciar no nível de vulnerabilidade da área de estudo as chuvas intensas. Nessa perspectiva, foram observados, entre outros aspectos, as questões relacionadas especificamente às ocorrências de alagamento de rua, deslizamento de terra, enchentes e inundação, bem como avaliado o grau de confiança da população em relação à equipe municipal da defesa civil e à opinião sobre a intensidade das chuvas.

Nesse sentido, a partir do levantamento realizado, foi possível verificar os principais fatores ou causas responsáveis pelos problemas de alagamento de rua, deslizamento de terra e enchente/inundação. Assim sendo, a partir da opinião da população entrevistada, constatou-se que aproximadamente $48,96 \%$ consideraram o lixo como causa principal para a ocorrência dos alagamentos de rua (Figura 4). Esse resultado sugere que uma parcela significativa dos moradores das áreas vulneráveis às chuvas tem clarividência suficiente para identificar uma das importantes causas motivadoras para o surgimento desse referido tipo de problema. 
EM

Já em relação aos deslizamentos de terra, as principais causas apontadas estão relacionadas às chuvas $(29,12 \%)$, desmatamento $(24,32 \%)$ e o lixo $(20,32 \%)$, perfazendo juntas um total de $73,76 \%$ das opiniões. Considerando-se que esse tipo de problema pode ocorrer de forma natural ou induzida, as causas mais comuns para o seu surgimento estão intimamente ligadas às chuvas e ao desmatamento. No entanto, uma possível explicação para a quantidade razoável das indicações do lixo como causa principal desse tipo de problema na área de estudo, pode estar associada ao descarte inadequado dos rejeitos nas encostas e grotões, que, por sua vez, tem sido motivado pela deficiência no serviço de coleta. Observando a Figura 4, é possível constatar que o lixo representou uma parcela relevante da população entrevistada, sendo considerado como causa principal em todas as situações analisadas: alagamento de rua, deslizamento de terra e enchente/inundação.

Ainda observando a Figura 4, verificou-se que na opinião dos entrevistados a chuva $(30,72 \%)$ foi considerada como a segunda maior causa da ocorrência de enchente/inundação, ficando atrás apenas do lixo, que representou em torno de 1/3 (33,60\%) das opiniões. Ambas as indicações podem ser admitidas como possibilidades quando da ocorrência de uma enchente/inundação, uma de maneira direta devido à precipitação pluviométrica acima da normalidade e em curto tempo, e a outra de forma indireta como ação indutora no processo de assoreamento dos cursos d'água.

Figura 4 - Distribuição percentual das causas principais para as ocorrências de alagamento de rua, deslizamento de terra e enchente/inundação.

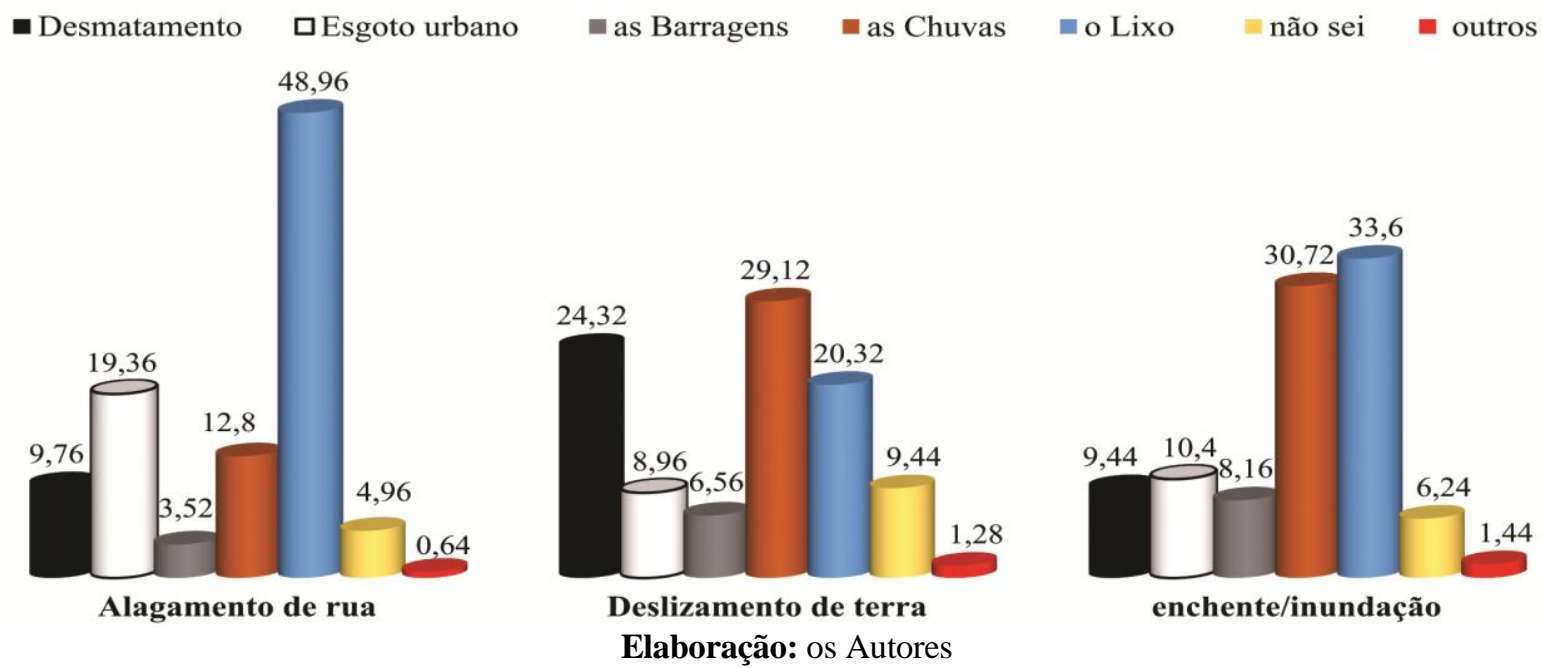

Contudo, considerando-se que tem sido comum durante as chuvas em grande quantidade e em curto intervalo de tempo os sistemas de drenagens naturais ou construídos 
EM

QUESTÃO

V.14 N. $01 \bullet 2021$

pág. 180-208

serem incapazes de dar vazão apropriada devido à obstrução das galerias, os resultados relacionados ao lixo também sugerem que uma parcela dos entrevistados pode ter confundido esse tipo de problema com o alagamento de rua. Tal fato pôde ser verificado por meio da opinião das pessoas em relação à frequência com que esse tipo de problema ocorre em seu bairro ou cidade (Figura 5).

Figura 5 - Distribuição percentual da frequência com que os problemas relacionados às chuvas ocorrem na RMM.

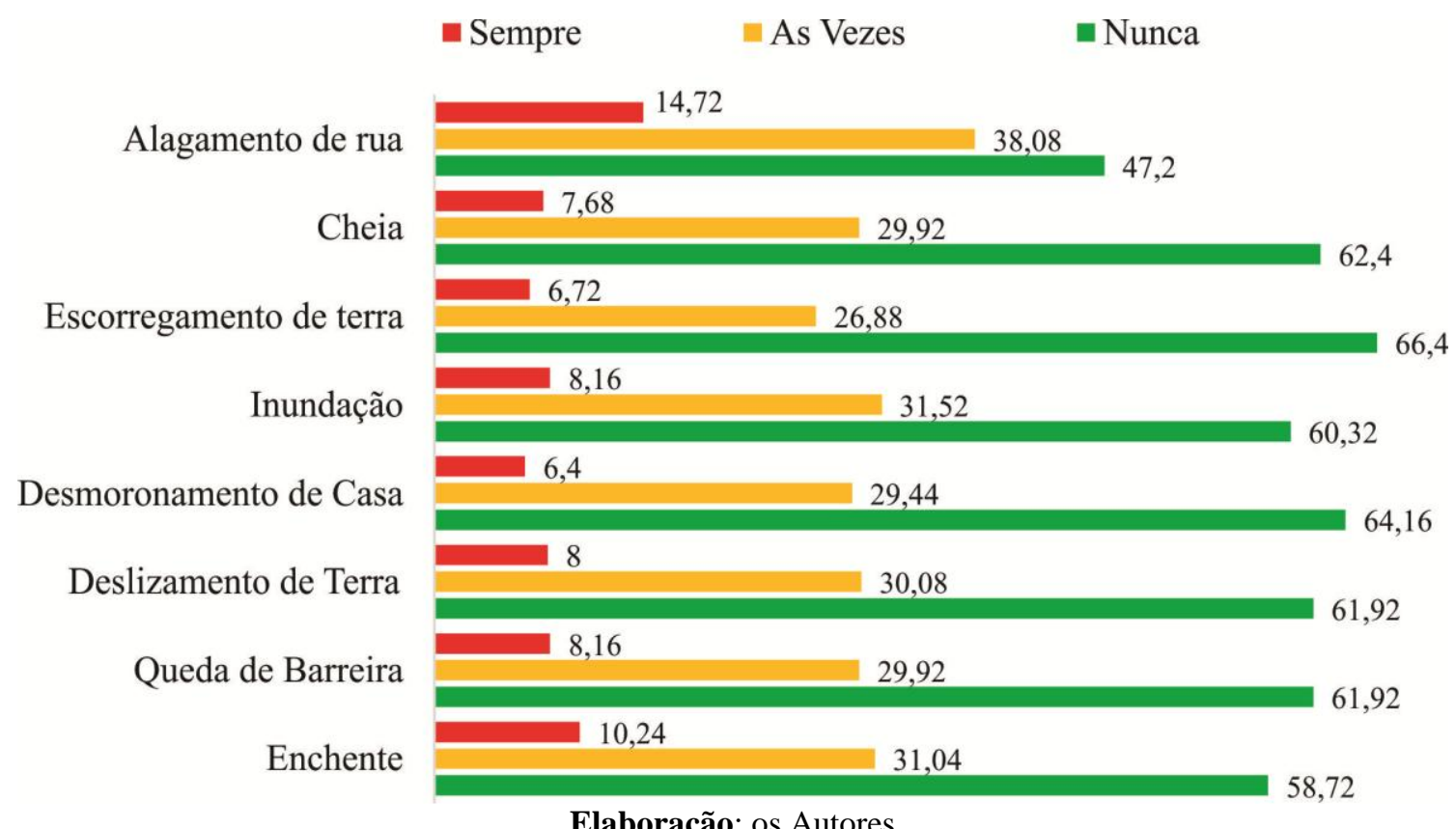

Ao se considerar que nessa etapa utilizou-se a escala de resposta psicométrica desenvolvido por Likert (1932) relativa à frequência, vale ressaltar que durante a aplicação dos questionários observou-se que os pontos âncoras (Nunca e Sempre) foram facilmente compreendidos, mas o termo intermediário (Às Vezes) para alguns entrevistados apresentou alguma dificuldade semântica.

Assim sendo, na opinião da maior parte da população entrevistada, os problemas relacionados a alagamento de rua, cheia, escorregamento de terra, inundação, desmoronamento de casa, deslizamento de terra e enchente predominou a opção Nunca ocorre quando chove (Figura 5). Dentre os resultados obtidos, destacam-se os escorregamentos de terra e desmoronamento de casa como problemas que Nunca ocorrem quando chove, respectivamente, 66,40\% e 64,16\% dos entrevistados. Ao contrário disso, o alagamento de rua foi considerado como o problema mais frequente, ou seja, na opinião de $14,72 \%$ da população entrevistada a sua ocorrência no bairro tem sido Sempre quando chove. 
EM

QUESTÃO

V.14 N. $01 \bullet 2021$

pág. 180-208

A queda de barreira, o escorregamento e deslizamento de terras podem ser considerados modalidades distintas para um mesmo tipo de problema. Assim sendo, na opinião de 22,88\% (143 pessoas) dos entrevistados, tal problema em seus respectivos bairros costuma Sempre ocorrer quando há precipitação pluviométrica.

Os assuntos relacionados aos extremos climáticos, especialmente sobre aquecimento global, têm sido alvo de estudo da comunidade científica internacional e feito parte da pauta de interesse das principais agências de notícias do Mundo. Embora a referida temática tenha despertado a atenção da imprensa brasileira, a cobertura jornalística quase sempre tem sido associada à ocorrência de algum tipo de desastre, muitas vezes, deixando em segundo plano as recentes descobertas científicas.

Se, por um lado, tal postura pode diminuir o importante papel que a imprensa nacional pode ser capaz de desempenhar como formador da opinião pública, fortalecendo o debate sobre a criação de uma agenda de mitigação ou adaptação ao aludido fenômeno climático, por outro lado, é possível reconhecer a contribuição que esse formato de matéria jornalística pode oferecer, tornando visível os problemas associados aos extremos climáticos, internalizando-o como parte da vida das pessoas.

Tendo em vista, que os problemas socioambientais motivados por fenômenos climáticos na área de estudo ocorrem durante o período chuvoso, causando impactos diretos à vida das populações atingidas, a opinião sobre a intensidade das chuvas pode ser capaz de revelar uma pseudo sensação de segurança. Assim sendo, foi verificado que $72,64 \%$ dos entrevistados acreditam que a intensidade das chuvas está diminuindo. Isso não significa que tal impressão seja verdadeira, mas pode resultar em uma falsa sensação de insegurança, especialmente entre as populações residentes em áreas vulneráveis.

A redução do número de vítimas em áreas vulneráveis às chuvas intensas depende da ação preventiva ou cautelar adotada pelo gestor público ou pela própria população residente, especialmente nas áreas já consideradas de risco. No caso do estado de Alagoas, a área de estudo dispõe de uma central de monitoramento assistida por um radar meteorológico. Todavia, a alternativa mais eficiente sobre as possíveis ocorrências de chuvas ainda continua sendo as emissoras de televisão, através dos boletins meteorológicos de tempo, isto é, a denominada previsão do tempo. A credibilidade das informações transmitidas oferece vantagens que podem salvar vidas, mas quando duvidosas podem transformar esse serviço de utilidade pública alvo de críticas severas, levando-o ao descrédito por parte da população. Assim sendo, foi observado que somente $14,40 \%$ dos entrevistados Sempre confiam na 
EM

QUESTÃO

V.14 N. $01 \bullet 2021$

pág. 180-208

previsão do tempo divulgada pelos meios televisivos de comunicação; em torno de $37,60 \%$ Nunca confiam e ÀS Vezes $48 \%$ da população admitem confiar.

No caso da administração pública, na medida em que a sensação de segurança da população aumenta, as solicitações por melhorias na infraestrutura são demandadas aos órgãos governamentais, e mais traumática se torna a aplicação dos instrumentos normativos de gestão do território ou até mesmo a intervenção do poder público para reduzir a presença de pessoas em áreas vulneráveis ou já classificadas como de risco. Vale ressaltar que esse tipo de dificuldade não deve ser admitido como justificativa aceitável para eventual inoperância do gestor público, especialmente durante a implementação dos programas de prevenção e combate aos problemas de ordem social ocasionados pelas chuvas intensas.

À medida que as áreas socialmente vulneráveis se tornam mais adensadas, observou-se através dos levantamentos de campo que as relações de dependência da população com o lugar se intensificam. Embora os serviços básicos de educação, saúde, transporte, esgotamento sanitário, segurança pública, entre outros, tenham sido considerados deficientes, verificou-se que mais da metade da população entrevistada $(54,24 \%)$ avaliaram como Bom e Ótimo o nível da qualidade de vida em seus respectivos bairros (Figura 6).

Figura 6 - Distribuição percentual da população entrevistada sobre a qualidade de vida nas localidades onde vivem.

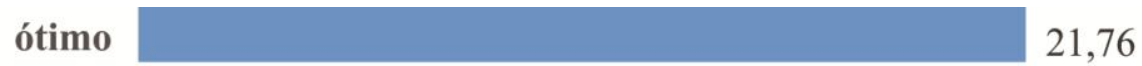

Bom

Regular 27,2

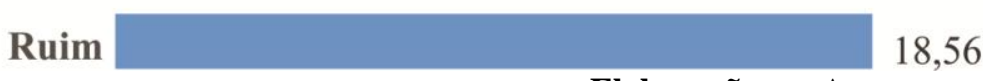

Elaboração: os Autores

A aparente satisfação da maior parte da população entrevistada sobre a qualidade de vida não é condizente com as condições adversas encontradas em seus bairros; pelo contrário, ela reafirma a suposição de dependência e o alto nível de vulnerabilidade social dessas comunidades. É óbvio que o contexto socioeconômico pode ser admitido como a principal razão capaz de explicar a insistência dos indivíduos em permanecer residindo em áreas vulneráveis às chuvas intensas, algumas delas já classificadas como áreas de risco iminente. 
No contexto da vulnerabilidade socioambiental às chuvas intensas em que predominam habitações precárias, a violência, o desemprego e um deficiente serviço de saneamento básico, apesar da suposta dependência, certamente a maioria da população anseia por mudanças. Tal fato foi observado quando, sem hesitação, a maioria dos entrevistados $(73,28 \%)$ declarou desejar viver em outro local ou cidade. Certamente esse resultado reflete verdadeiramente a insatisfação da população em relação à qualidade de vida desejada pelos habitantes dos municípios em análise.

Para WHOQOL (1997), a qualidade de vida reconhece o contexto da cultura e sistema de valores nos quais os indivíduos vivem e em relação aos objetivos, expectativas, padrões e preocupações idealizados por eles. Portanto, a partir das incursões em campo e dos resultados obtidos em relação à opinião da população entrevistada, é possível admitir a existência de uma tênue ligação das pessoas com o lugar onde vivem. Isso significa que possivelmente uma parcela significativa da população não tem sido plenamente atendida em suas necessidades básicas, inclusive quanto aos problemas advindos das chuvas e que atingem localidades demograficamente representativas dos doze municípios analisados.

$\mathrm{Na}$ última década, os eventos relacionados aos extremos climáticos têm sido mais frequentes, causando diversos problemas socioambientais; os prejuízos tornam-se substancialmente evidentes em áreas habitadas, especialmente nas grandes cidades e regiões metropolitanas. No caso específico das chuvas intensas, o agravamento dos impactos negativos tem sido associado à ocupação desordenada decorrente da falta de planejamento adequado. Para Benevides (2009, p. 2), os modelos de desenvolvimento implementados pelos países emergentes, como o caso do Brasil, adotaram uma série de medidas econômicas que acabam por trazer em seu bojo a exclusão de uma parcela da população em condições de miséria, bem como a ausência de um planejamento urbano adequado que vise distribuir a terra urbana de forma justa entre os moradores da cidade.

A conjugação desses fatores antropogênicos e naturais tem potencializado os prejuízos, de maneira a comprometer a capacidade de suporte dos ambientes, além de aumentar ainda mais as condições de vulnerabilidade, e, consequentemente, as possibilidades de perdas humanas e materiais. Nesse contexto diversificado de causas e efeitos, surge como estratégia eficaz para solucionar os problemas a implementação de programas de educação ambiental com vistas a definir paradigmas que considerem a sustentabilidade socioambiental como fator determinante na consolidação do desenvolvimento local. 
Para Oliveira (1998, p. 19), a natureza desses programas de educação ambiental deve ser fundamentada em um processo contínuo de aprendizado, análise e reflexão das ações dos indivíduos. Independentemente das condições socioeconômicas a que esses indivíduos estão submetidos, a compreensão deles sobre um determinado problema ou mesmo uma temática ambiental pode ser considerada como fator determinante para o resultado exitoso quando da implementação de um programa de sensibilização socioambiental ou até mesmo a consolidação de novos modelos de desenvolvimento.

\section{Considerações finais}

À guisa de uma conclusão, pode-se admitir que a caracterização das condições socioculturais e econômicas das populações vulneráveis às chuvas intensas são contribuições importantes ao desenvolvimento de estratégias de prevenção ou contingenciamento. Corroborando tal premissa, Tuan (1980, p. 1) considera que a busca pela compreensão da percepção do indivíduo sobre os problemas ambientais seja base necessária para o alcance de soluções eficientes. Contudo, as ressalvas destacadas por Eustáchio e Távora $(1999$, p. 1) alertam para o fato de que o exercício de identificar os problemas ambientais e a forma como estes interferem na qualidade de vida dos indivíduos têm sido uma questão bastante abstrata.

Para Lopes et al (2011, p. 141) a produção de conhecimento ocorre pela via compreensiva, em oposição à via explicativa. Nessa perspectiva, o sujeito interpreta o mundo à sua volta, assim como se autointerpreta como sujeito constituinte da história; concomitantemente, há a produção de sentidos. Para estes autores, as relações com o meio ambiente são permeadas de sentidos histórico-culturais diversos, e não meramente de caráter naturalista/biológico.

Dessa maneira, o estudo sobre o comportamento do indivíduo capaz de influenciar as decisões coletivas é fundamental para compreender os fatores socioculturais, econômicos e psíquicos que podem atuar sobre a opinião pessoal ou coletiva acerca de uma situação ou de determinada temática. Oliveira (2006, p. 35) considera que cada indivíduo tem sua interpretação de espaço, de acordo com a realidade em que vive. O espaço vivenciado é que será refletido nas percepções e esse parâmetro justifica a necessidade de compreender as ações de cada indivíduo, pois cada um tem uma opinião diferente. No entanto, não existe opinião/percepção errada ou inadequada, existem, sim, percepções diferentes, condizentes com o espaço vivido. 
EM

QUESTÃO

Neste sentido, observou-se que a $2 / 3(66,40 \%)$ da população reconhecem que as chuvas intensas são capazes de causar prejuízos as áreas urbanas das principais cidades da região metropolitana de Maceió, porém mais da metade dos entrevistados (50,56\%) não se sentem incomodados durante o período chuvoso. O reflexo da falta de percepção das pessoas pode influenciar de maneira decisiva nas relações socioambientais, as quais, por sua vez, tendem a favorecer ainda mais os efeitos e as proporções dos desastres sobre as comunidades afetadas $^{5}$. Casazza (2012, p. 63) assevera esses aspectos ao destacar que os estudos de percepção devem revelar importantes informações acerca do julgamento dos indivíduos sobre os ambientes nos quais vivem ou com os quais de alguma forma se relacionam.

Portanto, dentre os resultados alcançados sobre a opinião da população entrevistada, entre outros fatores importantes, observou-se que os problemas decorrentes das chuvas causam prejuízos imensuráveis à vida dos habitantes das áreas visitadas, além de perdas materiais, a população residente nas áreas vulneráveis sofre constantemente com a sensação de abandono por parte dos gestores e representantes públicos, no qual cerca de $78.72 \%$ classificaram como ruim a presença do poder público municipal em seus bairros.

Finalmente, cabe destacar que sob o ponto de vista prático, os resultados do presente estudo podem subsidiar os gestores e técnicos com dados e informações elementares para desenvolvimento de programas preventivos capazes de minimizar os problemas advindos das chuvas intensas na área estudada, além de auxiliarem as defesas civis municipais na elaboração de medidas para redução de prejuízos às populações residentes em áreas consideradas de riscos.

\section{Referências}

ALMEIDA, Fernando. Os desafios da sustentabilidade: uma ruptura urgente. Rio de Janeiro: Campus/Elsevier, 2007, p. 280.

ANDRADE, M. C. Usinas e Destilarias em Alagoas. Maceió: EDUFAL, 2. ed., v. 1, 140 p. 2010.

BARROS, R. P. de, MENDONÇA, R. A educação e o processo de determinação dos salários no Nordeste brasileiro. Rio de Janeiro: IPEA, 1997, 12 p.

BARROS, R.T.V et al. Saneamento (Manual de Saneamento e Proteção Ambiental para os Municípios, 2).. Belo Horizonte: Escola de Engenharia da UFMG, 1995, 221 p.

BENEVIDES, A. Diagnóstico socioambiental das áreas de risco em Fortaleza, Ceará. In: XII Encuentro de Geógrafos de América Latina. Montevideu, abril de 2009. Anais... XII Encuentro de Geógrafos de América Latina, p. 1-12, 2009.

\footnotetext{
${ }^{5}$ Considerações do Ministério das Cidades por meio da Secretaria de Programas Urbanos tem considerado doi.org/10.48075/geoq.v14i1.24496
} 
EM

QUESTÃO

V.14 N. $01 \bullet 2021$

pág. $180-208$

CAMPBELL-LENDRUM, D.; CORVALAN, C. Climate Change and Developing-Country Cities: Implications for Environmental Health and Equity. Journal of Urban Health, v. 84, n. 1, p. 109- 117, 2007.

CASAZZA, E. F. Contribuições das análises de percepção ambiental à formulação e implementação de instrumentos de Gestão Ambiental Pública: projeto de lei da Área de Proteção e Recuperação dos Mananciais do Alto Juquery. Dissertação de Mestrado. PósGraduação em Ciência Ambiental. USP, São Paulo, 173 p. 2012.

COSTA, C. Maceió. Maceió: Catavento, 2001, 180 p.

COSTA, R. I. D. A importância dos indicadores de desenvolvimento dos municípios da AMUNOP. ENCONTRO DE ECONOMIA PARAENSE, 5., 2007, Pará UENP/FAFICOP. 2007. Disponível em: http://www.ecopar.ufpr.br/artigos/a_058.pdf. Acesso em: 27 maio 2014.

ESPINDOLA, T. B. A Geografia Alagoana ou Descrição física, política e histórica da província de Alagoas. Maceió: Catavento, 325 p. 2001.

EUTÁCHIO, J.A.V; TÁVORA, J.L.T. Metodologias de avaliação de ativos ambientais: uma comparação entre as medidas. In: III Encontro Nacional da sociedade brasileira de economia ecológico, 1999. Anais... III Encontro Nacional da sociedade brasileira de economia ecológico, p.1-12, 1999.

GIL, A. C. Métodos e Técnicas de Pesquisa Social. 6 ed. São Paulo: Atlas S.A, 2008. 220 p.

IBGE - Instituto Brasileiro de Geografia e Estatística. Produto Interno Bruto dos municípios do estado de Alagoas, 2011.

IBGE, Instituto Brasileiro de Geografia e Estatística. Banco de dados: Série Estados@. Disponível em: <www.ibge.gov.br> Acesso em: 12 de novembro de 2015.

IBGE, Instituto Brasileiro de Geografia e Estatística. Censo 2010. Disponível em: <www.ibge.gov.br> Acesso em: 25 de novembro de 2013.

IBGE, Instituto Brasileiro de Geografia e Estatística. Evolução da divisão territorial do Brasil 1872-2010. IBGE, Rio de Janeiro, 281p. 2011. Disponível em <www.ibge.gov.br> Acesso em: 12 de janeiro de 2014.

LIKERT, R. A technique for the measurement of attitudes. Archives of Psychology. v. 22, n. 140, p. 44-53, 1932.

LOPES, P. R.; SOUZA, I. F.; LEME, M.; BRANDÃO, J. A. V.; COSTA, R. M. G. F.; FIGUEIREDO, R. A. Diagnóstico socioambiental: o meio ambiente percebido por estudantes de uma escola rural de Araras (SP). Pesquisa em Educação Ambiental, v. 6, n. 1, p. 139-155, 2011.

MARANGONI, A. M. M. C. Questionários e entrevistas: algumas considerações. In: VENTURI, Luis Antonio Bittar. Praticando geografia: técnicas de campo e laboratório. São Paulo: Oficina de Textos, 2009. p.167-174. 
EM

QUESTÃO

V.14 N. $01 \bullet 2021$

pág. $180-208$

NASCIMENTO, M. C. Contribuição metodológica para seleção de indicadores de vulnerabilidade socioambiental por meio das geotecnologias à região metropolitana de Maceió. 2016. 212p. Tese (Doutorado em Geografia) - Instituto de Geociências e Ciências Exatas, Universidade Estadual Paulista Julio deMesquita Filho, Rio Claro, 2016.

NOGEUIRA, O. O emprego do questionário nas ciências sociais. In: Vozes de Campos do Jordão, experiências sociais e psíquicas do tuberculoso pulmonar no estado de São Paulo. Rio de Janeiro: FioCruz, 2009. p. 152-165.

OLIVEIRA, Elísio. Márcio. Educação Ambiental: uma abordagem possível. Instituto Brasileiro do Meio Ambiente e dos Recursos Naturais Renováveis. Coleção Meio Ambiente. Série Estudos: Educação Ambiental, n. 1, Brasília, DF, 1998. 154p.

OLIVEIRA, L., MACHADO, L.M.C.P. Percepção, Cognição, Dimensão Ambiental e Desenvolvimento com Sustentabilidade. In: Reflexões sobre a Geografia Física no Brasil. VITTE, A.C., GUERRA, A.J.T. (Org). Rio de Janeiro: Ed. Bertrand Brasil, 2004.

OLIVEIRA, N. A. S. A educação ambiental e a percepção fenomenológica, através de mapas mentais. Revista Eletrônica do Mestrado em Educação Ambiental. Rio Grande (RS), v.16, p. 32-46. 2006.

PNUD - Programa das Nações Unidas para o Desenvolvimento (2013). O Índice de Desenvolvimento Humano Municipal Brasileiro (Português). Brasília, DF, 2013, 96p.

TUAN, Y. Topofilia: Um estudo da percepção, atitudes e valores do meio ambiente. Tradução de Lívia de Oliveira. São Paulo: Difel, 1980.

WHOQOL - World Health Organization. Measuing Quality of Life. Programme on Mental Health - Division of Mental Health and Prevention of Substance Abuse, 12 p. 1997. 